\title{
Laboreal
}

Volume 11 №2 | 2015

Varia

\section{Qualidade de Vida no Trabalho (QVT): do assistencialismo à promoção efetiva}

Calidad de Vida Laboral (CVL): de la "asistencia" a la promoción efectiva Qualité de Vie au Travail (QVT): de l'"assistanat" à la promotion efficace Quality of Work Life (QWL): from "welfarism" to effective promotion

\section{Mário César Ferreira}

\section{OpenEdition}

Journals

\section{Edição electrónica}

URL: http://journals.openedition.org/laboreal/3552

DOI: $10.4000 /$ laboreal.3552

ISSN: 1646-5237

\section{Editora}

Universidade do Porto

\section{Refêrencia eletrónica}

Mário César Ferreira, « Qualidade de Vida no Trabalho (QVT): do assistencialismo à promoção efetiva », Laboreal [Online], Volume $11 \mathrm{~N}^{0} 2$ | 2015, posto online no dia 01 dezembro 2015, consultado o 08 outubro 2019. URL : http://journals.openedition.org/laboreal/3552 ; DOI : 10.4000/laboreal.3552

Este documento foi criado de forma automática no dia 8 outubro 2019

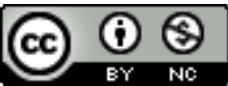

Laboreal está licenciado com uma Licença Creative Commons - Atribuição-NãoComercial 4.0 Internacional. 


\section{Qualidade de Vida no Trabalho (QVT): do assistencialismo à promoção efetiva}

Calidad de Vida Laboral (CVL): de la "asistencia" a la promoción efectiva Qualité de Vie au Travail (QVT): de l'"assistanat" à la promotion efficace Quality of Work Life (QWL): from "welfarism" to effective promotion

\section{Mário César Ferreira}

\section{NOTA DO EDITOR}

http://dx.doi.org/10.15667/laborealxi0215mcf

Manuscrito recebido em: janeiro/2015

Aceite após peritagem: junho/2015

\section{Introdução}

1 Qualidade de Vida no Trabalho (QVT) tem se tornado objeto de interesse social crescente. Numa consulta rápida e recente no poderoso motor de busca Google, usando a palavra-chave QVT nas línguas inglesa, francesa, italiana, espanhola e portuguesa encontramos mais de meio bilhão de links que remetem aos conteúdos desta temática $\mathrm{e}$ suas diferentes interfaces. No mundo do trabalho, o interesse aparece inequivocamente associado com o cenário de mundialização da economia e, sobretudo, com os efeitos negativos que processo de reestruturação produtiva vem produzindo no modo de funcionamento das organizações e nas vidas de seus principais protagonistas: os trabalhadores. A chamada "nova economia" - permanece em aberto o debate sobre o que ela tem de verdadeiramente novo - vem implantando novos modelos de gestão organizacional e do trabalho com o uso do suporte estratégico das Novas Tecnologias da Informação e Comunicação (NTICs). Tais inovações vem alterando o perfil das 
competências esperadas dos trabalhadores, as formas de se trabalhar, os dos locais de trabalho e as relações sociais. Estas metamorfoses se operam com base em um explícito discurso ideológico de se alavancar o crescimento, a rentabilidade, os ganhos, a produtividade. É um padrão de competitividade singular, orientado pelo frenesi da sobrevivência econômica. Compreender a importância e o papel destas mudanças para a Qualidade de Vida no Trabalho requer situar sua origem histórica e seus traços característicos principais.

2 As mudanças em curso que se operam nos contextos das organizações contemporâneas, resultantes do um processo de reestruturação da economia mundial, tem como período histórico de referência a década 1965-1975. Um conjunto de fatores (ex. aumento brutal do preço do petróleo; aumento das taxas de juros entre outros), agindo de modo associado, instalam uma crise no modelo de acumulação capitalista reduzindo drasticamente as taxas de mais-valia (Hobsbawm, 1996). Assim, a reestruturação produtiva (Albuquerque, 2011; Baumgarten \& Holzmann, 2011) foi se configurando com base em uma sinergia de agentes econômicos e governamentais visando harmonizar e compatibilizar as mudanças dos modelos de gestão e relações de trabalho com a introdução e uso intensivo da microeletrônica, a reformulação do aparato jurídico dos Estados nacionais e, principalmente, com medidas voltadas para liquidar com as barreiras comerciais (Mattoso, 1995). Esse processo de transformação ganha corpo e ritmo acelerado a partir das décadas de 1980-1990 (Castel, 2003; Leite, 2003; Leite, 1994; Mattoso, \& Baltar, 1996).

3 Alguns traços que marcam as metamorfoses do mundo corporativo são importantes para se compreender o cenário histórico no qual emerge o interesse pela Qualidade de Vida no Trabalho e, especialmente, de que forma ela tem ocupado as agendas de dirigentes, gestores, trabalhadores e também de pesquisadores de diversos campos que integram as chamadas ciências do trabalho e da saúde. Assim, cabe destacar:

- Mudanças de normas jurídicas que regulam as relações de trabalho e o próprio processo produtivo em dois níveis complementares: (a) no âmbito dos estados nacionais e das relações econômicas internacionais, introduzindo um conjunto de medidas focadas em mais liberdade para as relações de compra e venda de mercadorias, geração de tecnologias e intensificação do processo de comunicação.

- Mudanças no perfil das próprias organizações, introduzindo inovações que alteram normas, papéis e atribuições aos seus membros. Neste caso, a prescrição para o trabalho assume contornos distintos do padrão taylorista hegemônico.

- Investimento forte em novas tecnologias, com destaque para a automação e informatização do processo de produção de mercadorias e serviços, configurando um custo humano que parece aumentar os riscos para o trabalho saudável.

- Gestão organizacional e do trabalho, ancorada fortemente no uso de ferramentas informatizadas, que busca operacionalizar o enfoque do paradigma de flexibilização da produção (fabricação com base na demanda) e do trabalho (gerenciamento do tempo e dos resultados das atividades dos trabalhadores).

4 Além destes traços característicos do processo de mudanças, a reestruturação produtiva vem reconfigurando as relações de produção, distribuição e consumo, merecendo mencionar também (Antunes, \& Alves 2011): a mundialização da produção, da distribuição e do consumo; as redes globais de comunicação e informação; a interdependência dos mercados; as inovações tecnológicas nos âmbitos da microeletrônica, da microbiologia e das energias nuclear e ecológica; o crescente 
conhecimento científico e tecnológico agregados à produção; a redução do ciclo de vida das mercadorias; o aumento da terceirização de serviços; a redução do contingente tradicional dos trabalhadores na indústria, cedendo espaço para o crescimento das relações informais e precárias de trabalho (terceirizados, subcontratados, part-time) e da terceirização da economia; o crescimento do trabalho autônomo; a expansão do trabalho em domicílio e do teletrabalho; o aumento do trabalho feminino, especialmente nas modalidades de trabalho part-time, precarizado e desregulamentado; e a escolarização clássica amplia-se para o paradigma da qualificação contínua e a ultraespecialização vem evoluindo para a multiqualificação e a especialização flexível na execução das tarefas.

5 Além destas características, cabe ressaltar ainda que o mundo das corporações vem se tornando cada vez mais transnacional e, em certa medida mais volátil no tempo e no espaço, devido às empresas que migram de regiões e países.

6 Por fim, cabe mencionar que neste cenário de transformações o paradigma da flexibilização vem se afirmando como ferramenta gerencial para operacionalizar as mudanças produzidas pelo processo em curso de reestruturação produtiva. Na prática, ela tem se tornado uma diretriz no campo de gestão de processos produtivos voltada para tornar organizações e trabalhadores mais resilientes quanto às exigências de todas as ordens, impostas pela atual estágio histórico do capitalismo. A crítica de Sennett (2001) sobre o uso do paradigma da flexibilidade é reveladora de como ela se distancia daquilo que preconiza a Ergonomia em termos de adaptação do trabalho ao ser humano. Nesta perspectiva, vejamos o que escreveu Sennett (2001) sobre a flexibilização:

\footnotetext{
“A palavra 'flexibilidade' entrou na língua inglesa no século quinze. Seu sentido derivou originalmente da simples observação de que, embora a árvore se dobrasse ao vento, seus galhos sempre voltavam à posição normal. 'Flexibilidade' designa essa capacidade de ceder e recuperar-se da árvore, o teste e restauração de sua forma. Em termos ideais, o comportamento humano flexível deve ter a mesma força tênsil: ser adaptável às circunstâncias variáveis, mas não quebrado por elas. A sociedade hoje busca meios de destruir os males da rotina com a criação de instituições mais flexíveis. As práticas de flexibilidade, porém, concentram-se mais nas forças que dobram as pessoas." (p. 53)
}

7 O uso da "flexibilidade" nesta ótica apontada por Sennett está em sintonia com a crítica já bem conhecida da Ergonomia quando os modelos gerenciais tratam os trabalhadores como a variável de ajustes nos contextos corporativos (Wisner, 1994).

8 É com base neste cenário e seus ingredientes de mudanças que a dita "nova economia" almeja e investe para a configuração de um "novo trabalhador", cujo perfil de competências requer que este seja capaz de manter-se atualizado, manejar novas ferramentas tecnológicas e equipamentos sofisticados, atuar em ambientes com maior incerteza e papéis pouco definidos, ter habilidade para relacionar-se socialmente (ex. capacidade de negociação), lidar com problemas menos estruturados; e trabalhar cada vez mais em equipes.

9 Ocorre que as transformações econômicas e, sobretudo, as mudanças que invadem o mundo corporativo, em curso desde a década 1965-1975, não são neutros ou mesmo “indolores" para os trabalhadores. Os impactos no campo da saúde e segurança no 
trabalho são eloquentes das consequências negativas que o processo de reestruturação produtiva tem engendrado.

O relatório da Organização Internacional do Trabalho (OIT, 2013), proveniente de "Programa Sobre Segurança e Saúde no Trabalho e Meio Ambiente" apresenta um conjunto de dados ilustrativos, de natureza mundial, de como os contextos de trabalho, onde são produzidas mercadorias e serviços, vêm produzindo efeitos negativos para a saúde e a segurança dos trabalhadores. Neste sentido, cabe destacar alguns indicadores, tanto mundiais quanto da União Européia, absolutamente inquietantes (OIT, 2013):

- Estima-se que cerca de 2,34 milhões de pessoas morrem vítimas de acidentes ou doenças relacionadas com o trabalho. A maioria absoluta das vítimas - por volta de 2,03 milhões perde a vida devido a uma das diversas enfermidades profissionais existentes.

- Cerca de 6.300 mortes diárias relacionadas com o trabalho e estima-se que cerca de 5.500 delas são provenientes das diferentes doenças do trabalho.

- A incidência Transtornos Musculoesqueléticos (TME) em diversos países se constituem no tipo de enfermidade mais recorrente: em 27 estados membros da União Europeia, os TME são os de maior prevalência.

- As estatísticas europeias, em 2005, sobre doenças do trabalho apontam que os TME representam $59 \%$.

- A Organização Mundial de Saúde (OMS) aponta que, em 2009, cerca de 10\% de todos os anos de trabalho perdidos estão relacionados com os casos de TME.

- Os casos de estresse laboral estão relacionados com o assédio moral, sexual e a violência psicológica no trabalho e ele tem contribuído sobremaneira para o uso abusivo de álcool e o consumo de drogas.

- A vivência do estresse excessivo revela evidências clínicas de associação com problemas cardíacos, patologias musculoesqueléticas e digestivas.

11 Tais indicadores aparecem inequivocamente associados com o processo de reestruturação produtiva em curso. As transformações tecnológicas, sociais e organizacionais intensas e aceleradas que se observam nos ambientes de trabalho estão na gênese de riscos emergentes e de novos desafios para promoção da saúde e da segurança ocupacional. Neste sentido, a OIT chama a atenção para: o uso das nanotecnologias, determinadas biotecnologias; as condições ergonômicas deficientes; a radiação eletromagnética; e os riscos psicossociais diversos. É neste contexto, adverte a OIT, que se constata a prevalência de novos tipos de agravos para a saúde dos trabalhadores sem que haja medidas de enfrentamento por meio da prevenção, da proteção e do controle adequados e imprescindíveis.

O custo econômico que acompanha tais indicadores é também alarmante. Estima-se que os acidentes de trabalho e as enfermidades profissionais representem uma perda anual de $4 \%$ do Produto Interno Bruto no mundo. Neste caso, a fatura é alta, pois isto significa cerca de 2,8 bilhões de dólares estadunidenses em custos diretos e indiretos. Globalmente, estes dados parecem revelar um traço distintivo de nossa época: o trabalho como "modo de ganhar a vida" tem se transformado cada vez mais em risco de adoecimento e de acidentes e, muitas vezes, em "modo de perder a própria vida".

13 Neste panorama mundial com indicadores inquietantes o Brasil tem, infelizmente, a sua parcela de contribuição. Neste sentido, alguns dados são ilustrativos: o Brasil se situa na quarta posição mundial de acidentes com morte e o décimo quinto em acidentes considerados graves; em 2010 registraram-se 701.496 acidentes, entre estes 2.712 com morte, resultando num custo de cerca de $\mathrm{R} \$ 293$ milhões de reais em benefícios 
acidentários pagos pela Previdência (AEPS, 2010); em 2011 foram contabilizados 711.164 acidentes e doenças do trabalho, entre os trabalhadores assegurados da Previdência Social (AEPS, 2012). Analisando de perto este último indicador, constata-se: a ocorrência de 15.083 doenças relacionadas ao trabalho; o afastamento das atividades de 611.576 trabalhadores devido à incapacidade temporária (309.631 até 15 dias e 301.945 com tempo de afastamento superior a 15 dias), a incapacidade permanente de 14.811 e o óbito de 2.884 trabalhadores.

Em linhas gerais são estes os principais aspectos no qual se inscreve o interesse crescente no investimento em Qualidade de Vida no Trabalho (QVT) no mundo corporativo contemporâneo. Ele aparece, portanto, inequivocamente associado com o cenário de mundialização da economia e, sobretudo, com os efeitos negativos que processo de reestruturação produtiva vêm produzindo no modo de funcionamento das organizações, nos modos de trabalhar e nos impactos negativos para a saúde e a segurança no trabalho. Interesse presente, principalmente, nos países industrializados e que mobiliza diferentes protagonistas.

15 Com base neste panorama sucinto, é pertinente uma questão fundamental: se, de fato, Qualidade de Vida no Trabalho é importante, necessária e vem mobilizando a atenção de dirigentes, gestores e trabalhadores, o que as organizações efetivamente tem feito para a sua promoção nos contextos corporativos? O objetivo do texto consiste, portanto, em fornecer uma visão panorâmica das práticas hegemônicas de Qualidade de Vida no Trabalho (QVT) em organizações brasileiras, buscando evidenciar a sua natureza assistencialista e, sobretudo, seus limites para uma real melhoria dos indicadores de saúde e segurança.

\section{As práticas de Qualidade de Vida no Trabalho no Brasil: Perfil de uma perspectiva hegemônica e assistencialista}

16 Um balanço de pesquisas em Qualidade de Vida no Trabalho (QVT), conduzidas pelo Grupo de Estudos em Ergonomia Aplicada ao Setor Público (ErgoPublic) da Universidade de Brasília, possibilitou traçar um perfil característico das práticas de QVT em organizações brasileiras. Tal perfil é revelador de uma perspectiva hegemônica que caracteriza as práticas de QVT em organizações públicas, especialmente no âmbito federal brasileiro (Ferreira, Alves, \& Tostes, 2009). Neste sentido, alargando o campo de investigação, os resultados de uma pesquisa (amostra de conveniência) conduzida por Ferreira, Almeida, Guimarães e Wargas (2011) com empresas que vendem pacotes de serviços de QVT para organizações públicas e privadas brasileiras são ilustrativos dos tipos de programas mais frequentes existentes no Brasil: 


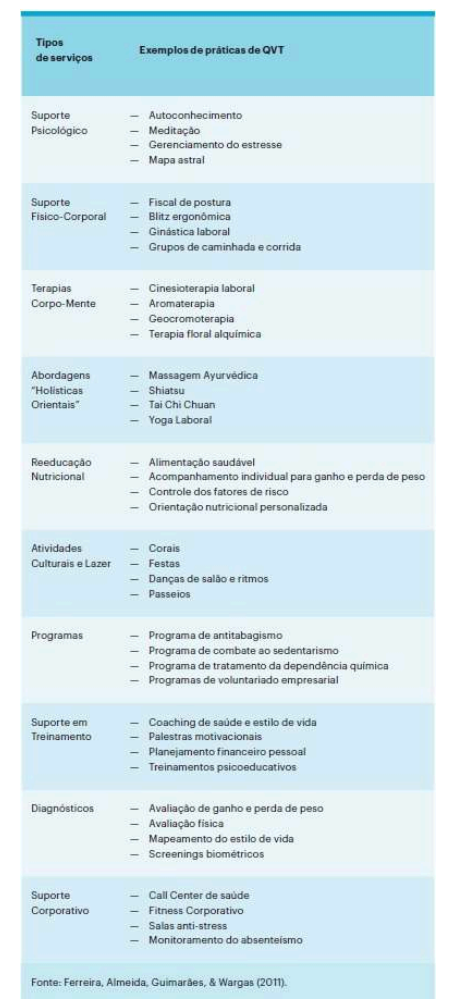

Fonte: Ferreira, Almeida, Guimarães, \& Wargas (2011).

17 Este "menu" de práticas de QVT revela a existência de um mercado diversificado e fecundo e, sobretudo, sugere, ainda, que os respectivos clientes parecem ser receptivos aos produtos oferecidos. No conjunto, esses tipos de serviços e exemplos de práticas que dão "corpo e forma" à abordagem assistencialista e hegemônica de Qualidade de Vida no Trabalho pode ser denominada como uma perspectiva de QVT do tipo "restauração corpo-mente" do público-alvo: os trabalhadores.

Essa abordagem hegemônica de Qualidade de Vida no Trabalho (QVT) permite identificar dois focos de interesse interdependentes:

19 (a) Foco na produtividade que se expressa no cotidiano das organizações por meio de designações diversas: "saúde corporativa", "bem-estar organizacional", "saúde organizacional", "necessidades da empresa", “otimizar custos”, “maximizar resultados", "rendimentos dos colaboradores"; e

20 (b) Foco no indivíduo, buscando fornecer ajuda/apoio/suporte para que os trabalhadores possam gerir as consequências negativas que nascem dos contextos de trabalho, por meio da "gestão do stress", "cuidados com a saúde emocional", "vivências em espaços anti-estresse", "imersão em atividades culturais e de lazer". Tal abordagem de QVT se apresenta também como instrumento efetivo para que as empresas possam gerir indicadores críticos bem conhecidos como, por exemplo, o absenteísmo, a falta de motivação e a rotatividade no emprego. Este "menu" de QVT que mais se assemelha a uma espécie de "ofurô corporativo" (Ferreira, 2013) se apresenta e se propõe ser alternativa segura para que as organizações alcancem seus objetivos e metas.

21 Enfim, essa perspectiva dominante de Qualidade de Vida no Trabalho (QVT) se apoia em um "cardápio" abundante em alternativas para, supostamente, cuidar dos efeitos nocivos às atividades dos trabalhadores nos ambientes de trabalho estressantes. 


\section{Crítica à Perspectiva Hegemônica e Assistencialista}

de "remédio" eficaz para gerir as transformações econômicas aceleradas e, sobretudo seus impactos no campo da saúde e segurança no trabalho. Entretanto, pode-se afirmar que, de fato, tais práticas de QVT apontadas se constituem em modos de dominação/ submissão dos trabalhadores que são próprios do capitalismo contemporâneo. Nele a maximização da produtividade permanece como um objetivo central, mas não explicitamente revelado, onde se instrumentaliza/empobrece o caráter coletivo do trabalho e se coloca a ênfase no indivíduo, na medida em que deslocam os problemas organizacionais para outras esferas. práticas de QVT prevalentes no caso brasileiro:

28 Foco no indivíduo. Tais práticas transferem aos trabalhadores a responsabilidade pela QVT, convocando-os para efetivamente participarem de tais atividades. As fontes concretas dos desgastes e da fadiga, cujas raízes são de natureza organizacional, permanecem intocáveis (ex. sobrecarga de trabalho; posto de trabalho não ergonômico). A crítica, feita de longa data, pela Ergonomia da Atividade permanece viva e atual: o trabalhador é a variável de ajuste, devendo, em tais casos, se adaptar ao ambiente organizacional hostil. Os programas de QVT buscam, de fato, aumentar a resistência física e mental dos trabalhadores para suportarem às adversidades organizacionais. Aqui o foco da flexibilidade, paradigma de gestão atual, personifica-se em cada trabalhador, conforme crítica formulada por Sennett (2001). 

organizações brasileiras coloca importantes desafios. Um conjunto de pesquisas, conduzidas com base numa abordagem em construção - denominada Ergonomia da Atividade Aplicada à Qualidade de Vida no Trabalho (EAA_QVT) - tem evidenciado que a promoção efetiva da QVT deve se apoiar no paradigma metodológico de perguntar aos trabalhadores como eles avaliam a qualidade de vida no trabalho nos seus contextos de trabalho (Ferreira, Ferreira, Paschoal, \& Almeida, 2014a; Ferreira, Ferreira, Paschoal, \& Almeida, 2014b). Esta é uma questão central para operacionalizar uma perspectiva de intervenção/transformação que, de fato, possibilite uma promoção de QVT de natureza sustentável e contra-hegemônica. Uma perspectiva que, no caso da EAA_QVT, constitui apenas o ponto de partida para um modelo analítico que combina macrodiagnóstico organizacional e microdiagnóstico ergonômico (Ferreira, 2008; Ferreira, 2011; Ferreira, 2012). 
$34 \mathrm{Na}$ dimensão do macrodiagnóstico, os resultados da EAA_QVT mostram que as principais fontes de mal-estar no trabalho estão associadas aos seguintes fatores: (a) condições de trabalho precárias (ex. ambientes insalubres; desconforto acústico); (b) organização do trabalho desumana (ex. metas que não respeitam os limites e capacidades do trabalhador; tarefas de ciclos curtos); (c) relações socioprofissionais conflituosas (ex. práticas de assédio moral no trabalho; tratamento descortês de clientes); (d) falta de reconhecimento no trabalho (ex. não valorização de soluções criativas; falta de reconhecimento social do trabalho); (e) reduzida ou nula perspectiva de crescimento profissional (ex. reduzida possibilidade de progressão na carreira); e (f) dificuldades para conciliar vida familiar/social e vida profissional (ex. falta de flexibilidade da jornada de trabalho). Assim, ter como referência central o ponto de vista dos trabalhadores e, principalmente, o que efetivamente se passa nas situações de trabalho como premissas para se conduzir diagnósticos e intervenções sustentáveis em Qualidade de Vida no Trabalho se constituem em importante diferencial analítico em face das práticas predominantes de QVT. Essa ótica para se repensar a Qualidade de Vida no Trabalho reafirma o pressuposto da Ergonomia da Atividade que preconiza adaptar o trabalho e seus múltiplos aspectos ao perfil e necessidades dos trabalhadores como modo mais seguro para alcançar eficiência, eficácia e bem-estar no trabalho.

\section{BIBLIOGRAFIA}

Albuquerque, P. P. (2011). Reengenharia. In A.D. Cattani, \& L. Holzmann (Orgs.), Dicionário de Trabalho e Tecnologia (pp. 315-319). Porto Alegre: Zouk.

Antunes, R., \& Alves, G. (2011). As mutações no mundo do trabalho na era da mundialização do capital. Educação \& Sociedade, 25(87), 335-351. Retirado em 15 de maio de 2015, de http:// www.scielo.br/scielo.php?script=sci_arttext\&pid=S0101-73302004000200003\&lng=pt\&tlng=pt. 10.1590/s0101-73302004000200003.

AEPS (2010). Anuário Estatístico da Previdência Social. Brasília: Ministério da Previdência Social. AEPS (2012). Anuário Estatístico da Previdência Social. Brasília: Ministério da Previdência Social. Athayde M., \& Brito, J. (2010). Vida, saúde e trabalho: Dialogando sobre qualidade de vida no trabalho em um cenário de precarização. Trabalho, educação e saúde, 7(3), 587-597.

Baumgarten, M., \& Holzmann, L. (2011). Reestruturação produtiva. In A.D. Cattani e L. Holzmann (Orgs.), Dicionário de Trabalho e Tecnologia (pp. 315-319). Porto Alegre : Zouk.

Castel, R. (2003). As metamorfoses da questão social: Uma crônica do salário. Petrópolis: Vozes.

Ehrenberg, A. (1991). La fatigue d'être soi. Dépression et société. Paris: Éditions Odile Jacob.

Ferreira, M.C. (2008). A Ergonomia da atividade se interessa pela qualidade de vida no trabalho? reflexões empíricas e teóricas. Cadernos de Psicologia Social do Trabalho, 11(1), 83-99. doi:http:// dx.doi.org/10.11606/issn.1981-0490.v11i1p83-99 
Ferreira, M.C. (2011). A Ergonomia da atividade pode promover a qualidade de vida no trabalho? reflexões de natureza metodológica. Revista Psicologia: Organizações e Trabalho, 11(1), 8-20.

Ferreira, M.C. (2012). Qualidade de Vida no Trabalho. Uma abordagem centrada no olhar dos trabalhadores. $2^{\text {a }}$ Ed. Revista e Ampliada, Brasília DF: Paralelo 15.

Ferreira, M.C. (2013). "QVT é quando acordo... Penso em vir trabalhar e o sorriso ainda continua no rosto!" Sentidos da qualidade de vida no trabalho na ótica dos servidores públicos. In M.C. Ferreira, C. Antloga, T. Paschoal, \& R.R. Ferreira (Orgs.), Qualidade de Vida no Trabalho. Perspectiva de Análise e Intervenção (pp. 19-38). Brasília: Paralelo 15.

Ferreira, M.C., Almeida, C.P., Guimarães, M.C., \& Wargas, R.D. (2011). Qualidade de Vida no Trabalho: a ótica da restauração corpo-mente e o olhar dos trabalhadores. In M.C. Ferreira, J.N.G. Araújo, C.P. Almeida, \& A.M. Mendes. (Orgs.), Dominação e Resistência no Contexto Trabalho-Saúde (pp. 159-182). São Paulo: Editora Makenzie.

Ferreira, M.C., Alves, L., \& Tostes, N. (2009). Gestão de Qualidade de Vida no Trabalho (QVT) no serviço público federal: o descompasso entre problemas e práticas gerenciais. Psicologia: Teoria e Pesquisa, 25, 319-327. http://dx.doi.org/10.1590/S0102-37722009000300005

Ferreira, M.C., Antloga, C., Paschoal, T., \& Ferreira, R.R. (Orgs.) (2013). Qualidade de Vida no Trabalho. Perspectiva de Análise e Intervenção. Brasília: Paralelo 15.

Ferreira, R.R., Ferreira, M.C., Paschoal, T., \& Almeida, J.G. (2014a). Perceptions of Quality of Work Life (QWL), Labor management practices and well-being: A inferential study in a brazilian IT company. In Proceedings of 28th International Congress of Applied Psychology, vol.1, 1-1, Paris, France.

Ferreira, R.R., Ferreira, M.C., Paschoal, T., \& Almeida, J.G. (2014b). Quality of Work Lifes Concept: What do workers of a public IT company in Brazil think?. In Proceedings of 28th International Congress of Applied Psychology, vol.1, 1-1, Paris, France.

Gaulejac, V. de (2007). Gestão como doença social: ideologia, poder gerencialista e fragmentação social. São Paulo: Ideias e Letras.

Hobsbawm, E.J. (1996). A era dos extremos: o breve século XX. Rio de Janeiro: Civilização Brasileira.

Leite, M. P. (1994). Reestruturação produtiva, novas tecnologias e novas formas de gestão da mãode-obra. In C.A. Oliveira (Org.), o mundo do Trabalho. Crise e mudança ao final do século (pp. 563-587). São Paulo: MTb-PNUD/Cesit-Unicamp/Scritta.

Leite, M. P. (2003). Trabalho e sociedade em transformação: Mudanças produtivas e atores sociais. São Paulo: Fundação Perseu Abramo.

Mattoso, J. (1995). A desordem do trabalho. São Paulo: Scritta.

Mattoso, J., \& Baltar, P. E. A. (1996). Transformações estruturais e emprego nos anos 90. In Cadernos do Cesit, 21, 1-23.

Medeiros, L.F.R., \& Ferreira, M.C. (2011). Qualidade de vida no trabalho: Uma revisão da produção científica de 1995-2012. Gestão Contemporânea, 1, 9-34.

Nardi, H. C. (2006). Ética, trabalho e subjetividade: trajetórias de vida no contexto das transformações do capitalismo contemporâneo. Porto Alegre: Ed. da UFRGS.

OIT- Organización Internacional del Trabajo (2013). La prevención de las enfermedades profesionales. Genebra, OIT.

Sennett, R. (2001). A corrosão do caráter: Consequências pessoais do trabalho no novo capitalismo. Rio de Janeiro: Editora Record. 
Wisner, A. (1994). A inteligência no trabalho: Textos selecionados de Ergonomia. São Paulo: Ministério do Trabalho MT/Fundacentro.

\section{RESUMOS}

No limiar do século XXI, a questão da Qualidade de Vida no Trabalho (QVT) vem se tornando no mundo corporativo um tema cada vez mais presente nas agendas de dirigentes e gestores. Tal interesse se inscreve num cenário que combina, concomitantemente, a reestruturação produtiva, o agravamento de indicadores negativos em saúde e segurança no trabalho e os riscos para o alcance de objetivos e metas corporativas. É neste contexto que as organizações têm investido cada vez mais em QVT. O objetivo do texto é fornecer uma visão panorâmica das práticas hegemônicas de Qualidade de Vida no Trabalho (QVT) em organizações brasileiras, buscando evidenciar a sua natureza assistencialista e, sobretudo, seus limites para uma real melhoria dos indicadores de saúde e segurança. A superação do viés assistencialista requer resituar o protagonismo dos trabalhadores e suas atividades para uma efetiva promoção da Qualidade de Vida no Trabalho (QVT).

En el umbral del siglo XXI, la cuestión de la Calidad de Vida Laboral (CVL) se ha convertido en un tema en el mundo de las organizaciones cada vez más presente en las agendas de los directivos y gerentes. Tal interés es parte de un escenario que combina al mismo tiempo la reestructuración productiva, el agravamiento de los indicadores negativos en la salud y seguridad en el trabajo y los riesgos para el logro de objetivos y metas corporativas. En este contexto, las organizaciones han invertido cada vez más en la CVL. El artículo tiene como objetivo proporcionar una visión general de las prácticas hegemónicas de la CVL en organizaciones brasileñas con el fin de mostrar su natural "asistencia" y en especial sus límites para una verdadera mejora de los indicadores de salud y seguridad. Superar el rasgo de "asistencia" requiere resituar el protagonismo de los trabajadores y de sus actividades para la promoción efectiva de la calidad de vida laboral.

Au seuil du XXI siècle, la question de la Qualité de Vie au Travail (QVT) est devenue un thème dans le monde des entreprises de plus en plus présent dans les agendas des dirigeants et des gestionnaires. Tel intérêt fait partie d'un scénario qui combine à la fois, la restructuration productive, l'aggravation des indicateurs négatifs en matière de santé et de sécurité au travail et les risques pour atteindre les objectifs des entreprises. Dans ce contexte, les organisations ont de plus en plus investi dans la QVT. Cet article vise à apporter un aperçu général des pratiques hégémoniques de la QVT dans les organisations brésiliennes, afin de mettre en évidence leur nature "d'assistanat" et, surtout, ses limites pour une réelle amélioration des indicateurs de santé et de sécurité. Pour surmonter le biais de l"'assistanat" il faut resituer le rôle des travailleurs et de leurs activités, en tant que protagonistes, pour la promotion efficace de la qualité de vie au travail.

On the threshold of the $21^{\text {st }}$ century, the issue of Quality of Work Life (QWL) is becoming more and more important on the agendas of leaders and managers from the corporate world. This interest arises in the midst of a scenario that combines, concomitantly, the restructuring of productivity, the worsening of negative indicators for health and safety at work and also the risks associated with reaching corporate goals and objectives. It is in this context that organizations are increasingly investing in QWL. The aim of this text is to provide a 360 degree analysis of the hegemonic QWL practices found in Brazilian organizations, with the intention of providing evidence of their "welfaristic" nature, and, moreover, of their limitations for a genuine improvement in health and safety indicators. Overcoming a "welfaristic" bias requires returning 
workers and their activities to the role of protagonists for the effective promotion of Quality of Work Life.

\section{ÍNDICE}

Palabras claves: calidad de vida laboral, bienestar, promoción, actividad Mots-clés: qualité de vie au travail, bien-être, promotion, activité

Keywords: quality of work life, "welfarism", promotion, activity

Palavras-chave: qualidade de vida no trabalho, assistencialismo, promoção, atividade

\section{AUTOR}

\section{MÁRIO CÉSAR FERREIRA}

Universidade de Brasília (UnB), Instituto de Psicologia, Departamento de Psicologia Social e do Trabalho, Núcleo de Ergonomia da Atividade, Cognição e Saúde (ECoS). Campus Darcy Ribeiro, ICC Sul, Asa Norte, Brasília DF CEP 70.910-900, Brasil

mcesar@unb.br 